\title{
Rare heterotopic pregnancy after frozen embryo transfer: a case report and literature review
}

\author{
Xianping Wang ${ }^{1 \dagger}$, Ding Ma ${ }^{2 \dagger}$, Yangang Zhang ${ }^{2}$, Yanhua Chen ${ }^{1}$, Yuxia Zhang ${ }^{1}$, Zhongyu Liu ${ }^{3}$ Xingyu Bi',
} Xueqing $\mathrm{Wu}^{1^{*}}$ and Junmei Fan ${ }^{1^{*}} \mathbb{D}$

\begin{abstract}
Background: Heterotopic pregnancy occurred after frozen embryo transfer with two D3 embryos, and the case had a history of bilateral salpingectomy due to salpingocyesis. An ectopic heterotopic pregnancy was implanted in the left psoas major muscle, which has not been previously reported.

Case presentation: A 33-year-old woman presented with left back pain after curettage due to foetal arrest in the uterus without vaginal bleeding and spotting, and painkillers relieved the pain initially. When the painkillers ceased to work, the patient returned to the hospital. The $\beta$-human chorionic gonadotropin ( $\beta$-hCG) level remained increased compared with the time of curettage, and a diagnosis of retroperitoneal abdominal pregnancy was suggested by ultrasonography and computerized tomography $(\mathrm{CT})$ with the gestational sac implanted in the left psoas major muscle at the left hilum level. Laparotomy was performed to remove the ectopic pregnancy. During the operation, we carefully separated the adipose tissue between the space of the left kidney door and left psoas major muscle, peeled away the gestational sac that was approximately $50 \mathrm{~mm} \times 40 \mathrm{~mm}$ with a 25 -mm-long foetal bud, and gave a local injection of $10 \mathrm{mg}$ of methotrexate in the psoas major muscle. Fifty days later, $\beta-\mathrm{hCG}$ decreased to normal levels.
\end{abstract}

Conclusion: It is necessary to pay more attention to the main complaints to exclude rare types of ectopic pregnancies of the pelvis and abdomen after embryo transfer.

Keywords: Heterotopic pregnancy, Retroperitoneal, Laparotomy, Case report, Frozen embryo transfer

\section{Background}

Ectopic pregnancy is one of the most common acute abdominal diseases in obstetrics and gynaecology. It refers to a pregnancy in which the gestational sac is implanted outside of the uterine cavity, and the incidence of ectopic pregnancy is $2 \sim 3 \%$ [1]. Abdominal pregnancy accounts for $1 \%$ of ectopic pregnancies, and retroperitoneal pregnancy is a rare type of abdominal pregnancy, so only a few

\footnotetext{
*Correspondence: wuxueqq@hotmail.com; sxykdx333@sina.com

${ }^{+}$Xianping Wang and Ding Ma are contributed equally to this work. 'Children's Hospital of Shanxi and Women Health Center of Shanxi, Department of Reproductive Medicine Center, Taiyuan, Shanxi, China Full list of author information is available at the end of the article
}

cases have been reported worldwide [2]. However, the mortality of intraperitoneal pregnancy was 8 times higher than that of common pregnancy [3]. Heterotopic pregnancy refers to the coexistence of intrauterine pregnancy and ectopic pregnancy. With the development of IVFassisted pregnancy technology, the incidence of heterotopic pregnancy has been increasing, accounting for $1 \%$ of IVF pregnancies [4]. This report describes a case of heterotopic pregnancy that occurred after embryo transfer, with a history of bilateral salpingectomy due to salpingocyesis. The ectopic pregnancy was implanted in the left psoas major muscle, which was not previously reported

(c) The Author(s). 2020 Open Access This article is licensed under a Creative Commons Attribution 4.0 International License, which permits use, sharing, adaptation, distribution and reproduction in any medium or format, as long as you give appropriate credit to the original author(s) and the source, provide a link to the Creative Commons licence, and indicate if changes were made. The images or other third party material in this article are included in the article's Creative Commons licence, unless indicated otherwise in a credit line to the material. If material is not included in the article's Creative Commons licence and your intended use is not permitted by statutory regulation or exceeds the permitted use, you will need to obtain permission directly from the copyright holder. To view a copy of this licence, visit http://creativecommons.org/licenses/by/4.0/ The Creative Commons Public Domain Dedication waiver (http://creativecommons.org/publicdomain/zero/1.0/) applies to the data made available in this article, unless otherwise stated in a credit line to the data. 
[5]. Patient written consent was obtained, and the protocol was approved by the Ethics Committee of Shanxi Maternal and Child Health Care Hospital (IRB-KY-2017).

\section{Case presentation}

A 33-year-old pregnant woman, gravida 6, para 1, was hospitalized on August 10, 2019, 52 days after embryo transfer, presenting with 11 days of pain in the left lumbar back after curettage. The menstrual cycle was 29-30 days, 3-5 days, LMP: 2019-6-8. On June 19 , two $\mathrm{D}_{3}$ embryos $(10 \mathrm{C}, 2 ; 8 \mathrm{C}, 2)$ were thawed and transferred in the natural cycle. After transfer, luteal support was provided, including diprogesterone (Abbott, the Netherlands) 20 $\mathrm{mg}$, b.i.d., p.o. and progesterone (Xianju, China) $40 \mathrm{mg}$, q.d., i.m. The serum $\beta$-hCG increased from 8 days after embryo transfer (Fig. 1). Twenty days after transfer, the anechoic area in the uterus was $20 \mathrm{~mm} \times 10 \mathrm{~mm}$ by vaginal pelvic ultrasound, similar to the gestational sac. Thirty-five days after transfer, the anechoic area in the uterus was re-examined and found to be $19 \mathrm{~mm} \times 6 \mathrm{~mm}$, and accessory tissues showed no obvious abnormalities. Both laboratory data and ultrasound imaging results suggested embryo arrest, and curettage was performed on July 30 (41 days after transfer). Villus tissue was observed in the uterine cavity after the operation. On August 2nd, the patient experienced intermittent left back pain with distension and no relief. The patient took painkillers, and the pain was relieved without dizziness, anal distention, nausea or vomiting. On August 9th, the pathological result of curettage content validated the villous tissue supporting uterus pregnancy (Fig. 2). On August 10th, the patient experienced worse pain that was not relieved with painkillers. The vital signs of the patient were steady, and percussion pain of the left costal ridge angle was positive. The ultrasound of the pelvic cavity showed that the uterus was $49 \mathrm{~mm} \times 55 \mathrm{~mm} \times 44$ $\mathrm{mm}$ with regular shape, uniform echo of the myometrium, and a $17 \mathrm{~mm} \times 12 \mathrm{~mm}$ uneven echo area in the uterine cavity (Fig. 3 a). Colour Doppler flow imaging showed a small amount of blood flow, $25 \mathrm{~mm} \times 12 \mathrm{~mm}$ in the left ovary and $27 \mathrm{~mm} \times 15 \mathrm{~mm}$ in the right ovary. No echoic area was found in the Douglas pouch. Behind the left kidney, there was a $49 \mathrm{~mm} \times 39 \mathrm{~mm}$ heterogeneous echo area, which was similar to the gestational sac, a $36 \mathrm{~mm} \times 25 \mathrm{~mm}$ anechoic area. The crown-lump length of the embryo was $25 \mathrm{~mm}$, without primitive beating of heart tube, suggesting abdominal pregnancy (Fig. $3 \mathrm{~b} / \mathrm{c}$ ). The urgent $\beta$-hCG blood test was 74,678 $\mathrm{mIU} / \mathrm{ml}$. Retroperitoneal pregnancy was hinted. Then, abdominal CT showed that a round soft tissue density shadow could be seen in front of the left psoas major muscle, with dense liquid in the centre. The maximum diameter of the lesion was $36 \mathrm{~mm}$, and the maximum diameter of the low density was $25.7 \mathrm{~mm}$. The arteriovenous phase could be seen with venules entering. Occupying lesions of the left psoas major muscle at the middle and lower poles of the left kidney were

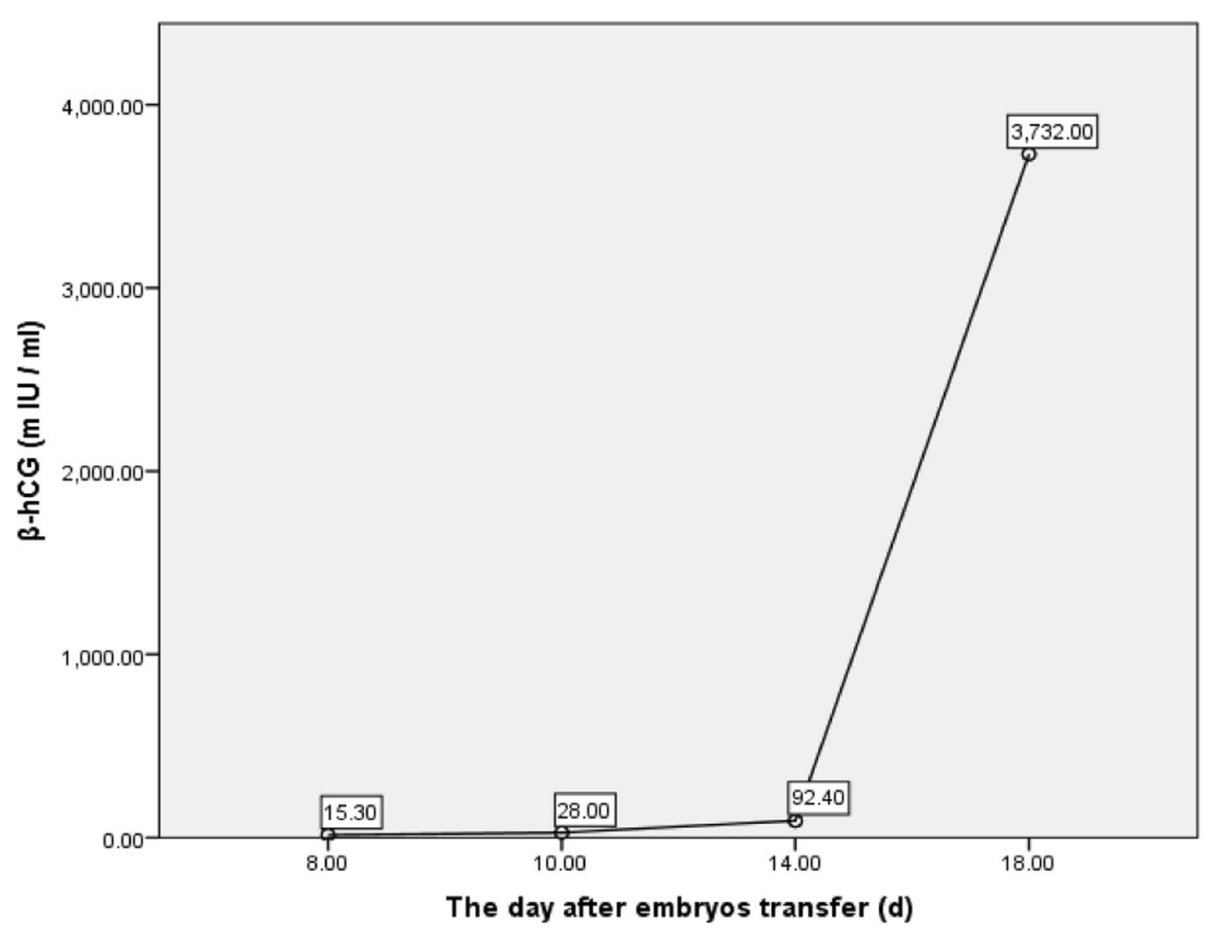

Fig. 1 The $\beta$-hCG changes after embryo transfer 


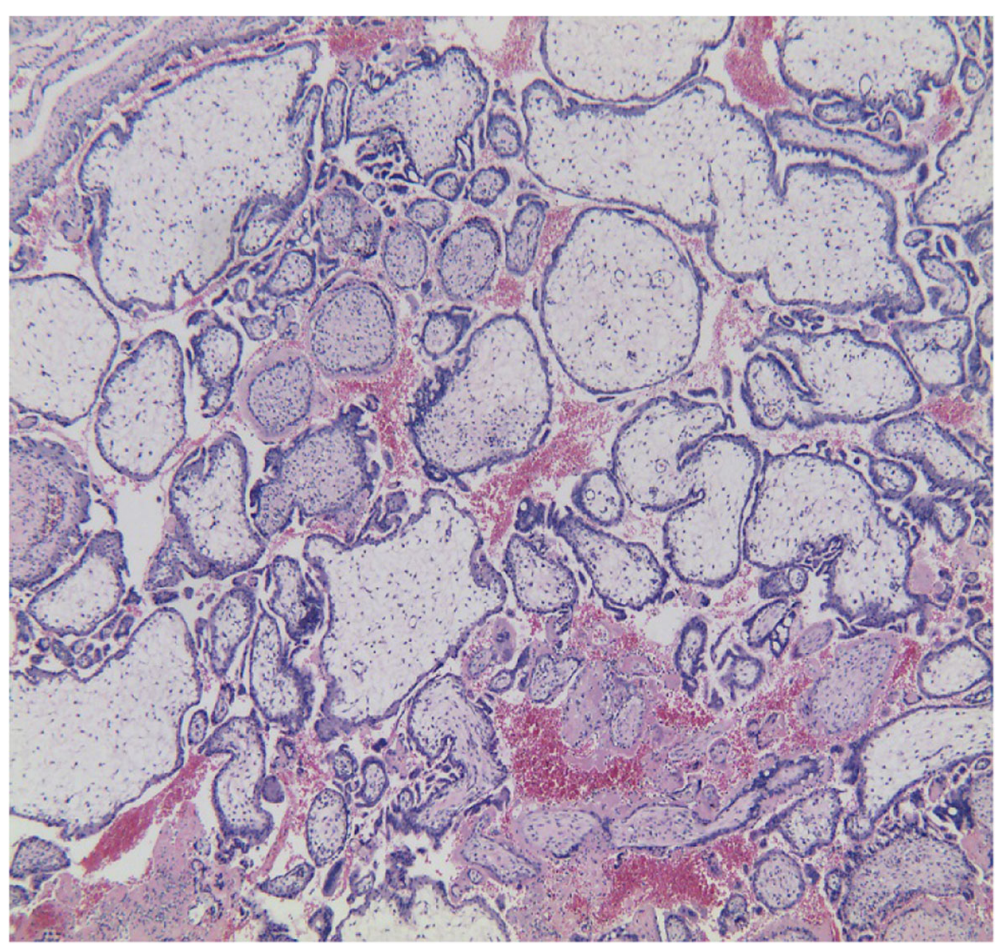

Fig. 2 Pathological result of curettage tissue (40 X)

considered (Fig. 4), and the diagnosis of ectopic pregnancy was established in combination with the history.

The patient had a spontaneous abortion in 2009, and a right salpingectomy was performed in 2010 due to an ectopic pregnancy of the right fallopian tube. In 2011, a baby girl was delivered vaginally at full term. In July 2012, an ectopic pregnancy of the left fallopian was treated with drugs. In 2013, salpingography showed that the left fallopian tube was unobstructed and that the right was absent. In June 2013, in vitro fertilization was performed, two $\mathrm{D}_{3}$ embryos were transferred, and laparoscopic left salpingectomy was performed due to the left fallopian pregnancy. In April 2019, two blastocysts were transferred in the natural cycle without pregnancy.

After admission, laparotomy was performed with a 15$\mathrm{cm}$-long incision between the 11th costal segment of the posterior axillary line, which was then gradually separated into the lower back fascia layer by layer, freed and removed to the 11th ribs to fully expose the operative field. Careful blunt separation of the retroperitoneal space was performed. At the position of the left renal

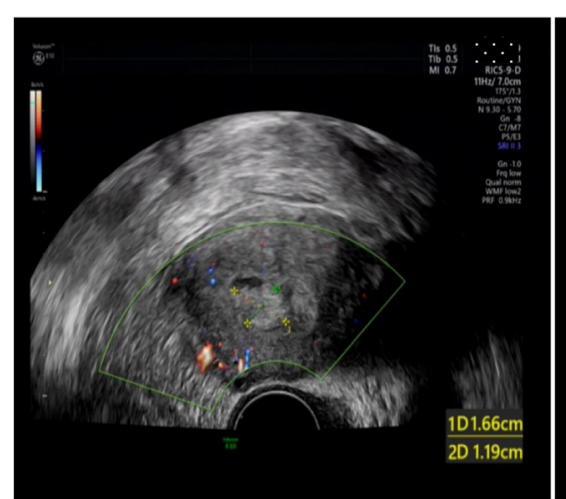

a

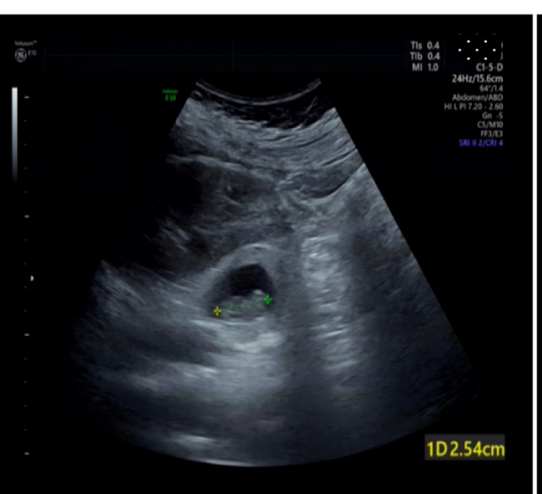

b

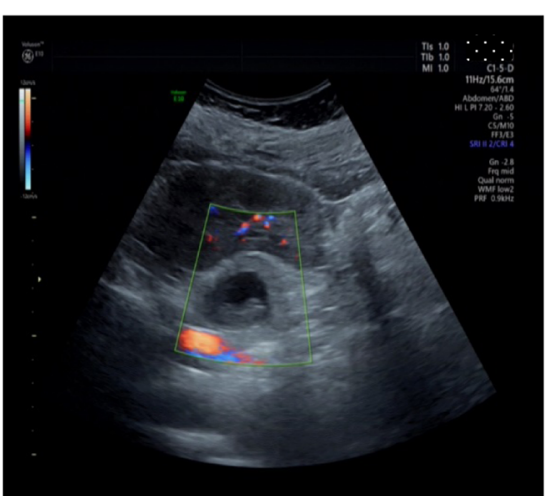

C

Fig. 3 The ultrasonograms before the laparotomy . a transvaginal ultrasonogram of uterus after curettage; b: the feotal bud of retroperitoneal pregnancy by transabdominal ultrasonogram; c: transabdominal colour Doppler ultrasonogram of retroperitoneal pregnancy 


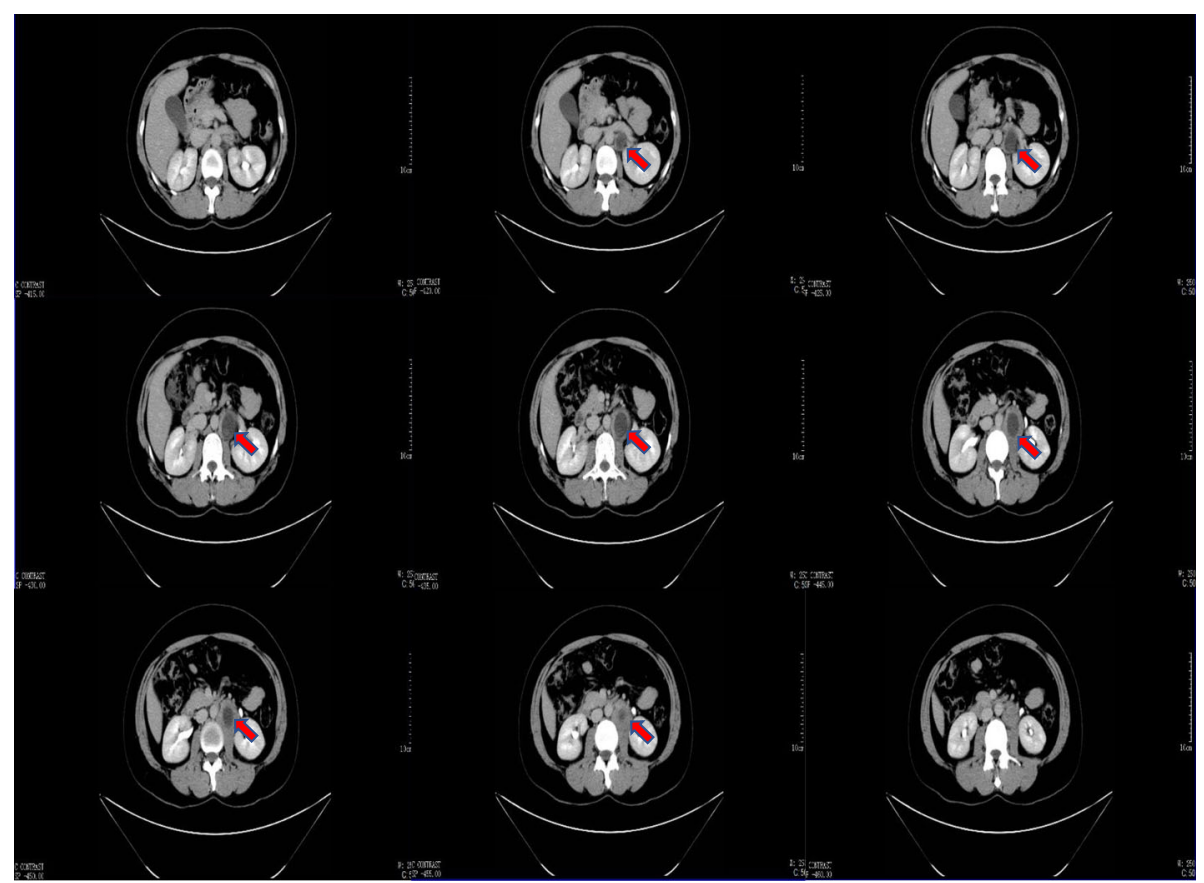

Fig. 4 Abdominal computed tomography of Axial plane. The cystic mass was indicated by red arrow was gestational sac

hilum, a gestational sac implanted in the left psoas major muscle was exposed, and the capsule was complete. After freeing of the tissue around the gestational sac, the gestational sac with a size of approximately $50 \mathrm{~mm} \times 40 \mathrm{~mm}$ was clearly exposed, and the foetal bud was approximately $25 \mathrm{~mm}$ long (Fig. 5). Sufficient haemostasis was achieved at the attachment of the gestational sac, and $10 \mathrm{mg}$ of methotrexate was injected locally. Before discharge, the patient expressed remorse for not communicating with doctors regarding the pain at the onset until painkillers were useless and appreciated the diagnosis and treatment in time. Fifty days later, blood serum $\beta$-hCG decreased to normal levels (Fig. 6).

\section{Discussion and conclusions}

Heterotopic pregnancy refers to pregnancy coexisting in the uterus and multiple parts outside of the uterus at the same time. The incidence in natural pregnancy is $1 / 30$, 000 [6], ovulation induction is $1 / 900$, and assisted reproductive technology is $1 / 100$ [7], while maternal mortality is 5/1,000,000 [8]. Abdominal pregnancy is a rare ectopic pregnancy, accounting for $1 \%$ of ectopic pregnancies [9], and the incidence is $1 / 10,000 \sim 1 / 3000[10,11]$. Abdominal pregnancy was reported in the Douglas pouch of the pelvis, serous layer of the uterus, appendages, abdominal organs, liver, omentum, intestine, appendix, retroperitoneal space, abdominal wall, etc. [5]. Rare ectopic pregnancy is usually misdiagnosed in the early stage until

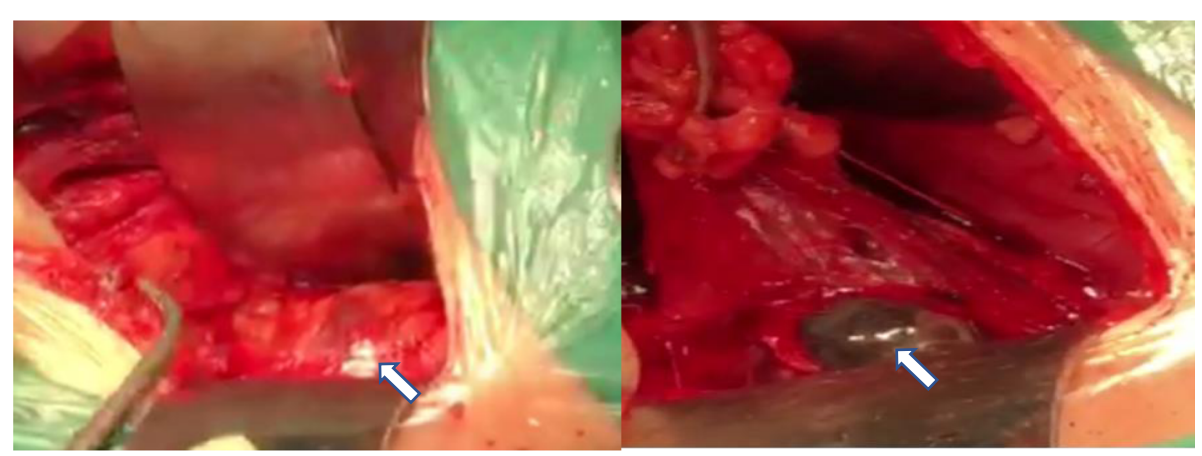

Fig. 5 The laparotomy view, the cyst mass implanted in left psoas major muscle (arrow) 

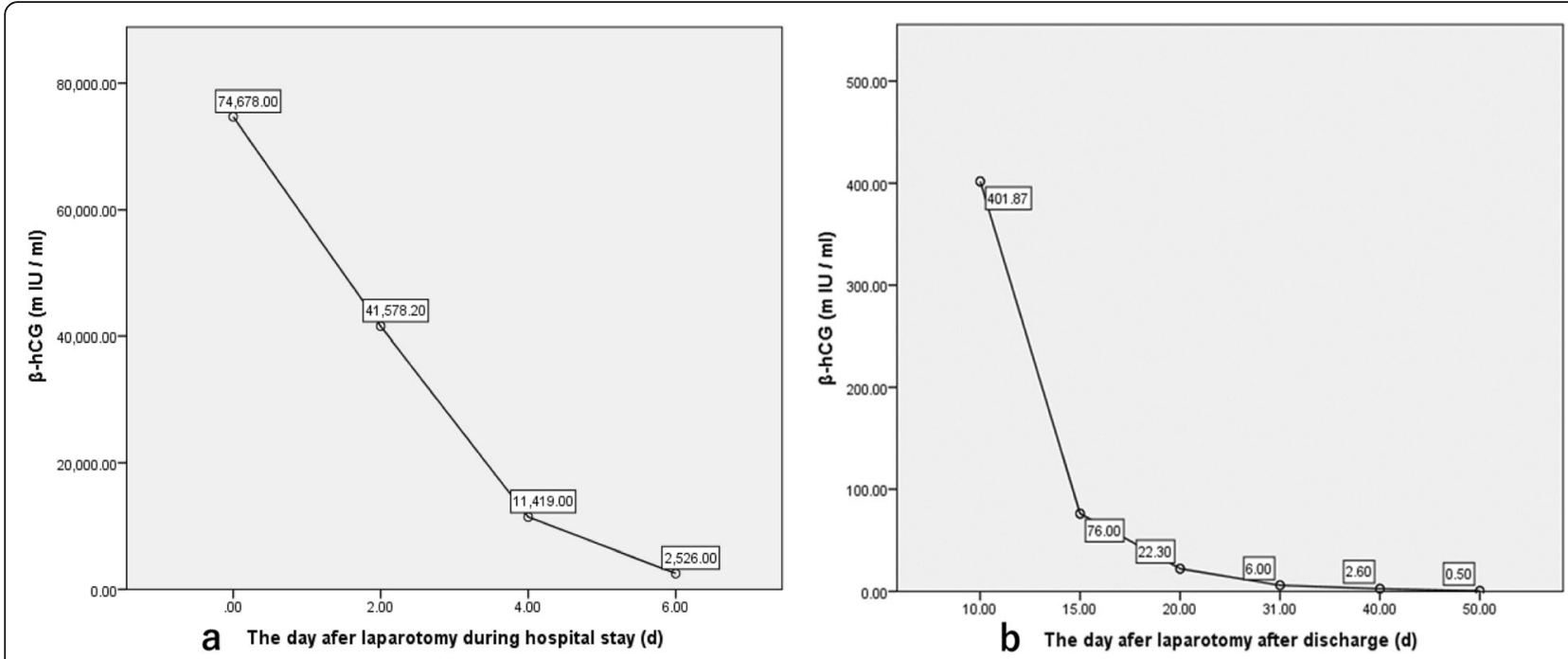

Fig. 6 The $\beta$-hCG changes after laparotomy

bleeding, pain and other symptoms occur [12]. Whether the early intrauterine pregnancy embryo survives or not, the situation of ectopic pregnancy or heterotopic pregnancy might be ignored, and if not diagnosed, these conditions can endanger the patient's life [13]. The blood $\beta$ hCG of the case was positive 8 days after two embryos were transferred and continued to increase. A similar gestational area was observed in the uterine cavity 35 days after transfer, but no embryo bud or yolk sac was found. In consideration of foetal arrest, uterine curettage was performed. Postoperatively, lumbago and back pain symptoms appearing outside the hospital might be caused by ectopic gestational sac growth resulting in stimulation of the nerve of the left psoas major muscle. At the beginning, the patient took painkillers, which led to a missed early diagnosis. According to the clinical symptoms, combined with the auxiliary examination, heterotopic pregnancy was made with the uterus, and retroperitoneal pregnancy was gradually arrested. For heterotopic pregnancy, if the intrauterine embryo survived and was diagnosed early, most of the cases could be successfully preserved by surgery [11]. If the diagnosis of abdominal pregnancy is later than 24 weeks, the mother is healthy, and the foetus is alive, on the basis of the informed consent of the couple, they could be admitted to the hospital to continue pregnancy [14]. However, some scholars held different opinions that abdominal pregnancy once diagnosed should be actively given surgical treatment due to the high mortality rate of mothers and foetuses and the high birth defect rate of new-borns [15].

This case of heterotopic pregnancy occurred after salpingectomy. There are some questions still to be clarified: how did the embryo enter the abdominal cavity from the uterine cavity, even arriving at the space between the retroperitoneal retrorenal fascia and psoas major muscle? How could the embryo implant in the psoas major? It has been reported that iatrogenic intraperitoneal pregnancy and embryo retrograde lead to retroperitoneal pregnancy [16]. No abnormal channels were found in the uterine cavity in hysteroscopy before this pregnancy. The embryo transfer was carried out under the guidance of ultrasound in our reproductive centre, and the CCD hose was selected. The whole transfer process was smooth, and we were aware that the transfer tube did not penetrate the uterus. Therefore, embryos free from the uterine cavity to the abdominal cavity caused by iatrogenic factors could be excluded. The kidney is one of the extraperitoneal organs, and its position is relatively fixed. The retroperitoneal space is the area between the parietal peritoneum and the fascia transversalis of the abdominal posterior wall. The retroperitoneal space is divided into the anterior pararenal space, the perirenal space and the posterior renal fascia space. In this case, the position of the ectopic pregnancy was located in the posterior renal fascia space, that is, between the posterior renal fascia, the lateral vertebral fascia and the fascia transversalis. There were liposomes in the postrenal space. The embryo was implanted in the psoas major muscle within this space, which has not been reported before. We speculated that the bilateral fallopian tube stumps of the patient after resection were spontaneously reperfused and that one embryo moved in a retrograde manner into the abdominal cavity. At the same time, the patient had a previous history of laparotomy and laparoscopic pelvic surgery, which affected the original anatomical structure of the pelvic cavity and abdominal cavity, resulting in abnormal channels between 
the abdominal cavity and retroperitoneum. The embryo retrogradely moved into the pelvic cavity through an abnormal channel, and under the promotion of intestinal peristaltic waves and body position changes, it arrived at the left renal hilum nearby, where loose pararenal liposomes might also provide necessary nutrients for embryo implantation in the psoas major muscle. Previous studies reported abdominal pregnancy after bilateral salpingectomy and inferred that there was a fistula leading to the abdominal pregnancy [17]. Others reported that during the implantation process after the disappearance of the zona pellucida, the cells with differentiation potential could fall off and be implanted in the capillaries or lymphatics, and with the circulation of blood or lymph, they would continue to grow in the retroperitoneum, resulting in retroperitoneal pregnancy, which is similar to the metastasis mechanism of gynaecological cancer; therefore, the implantation site of ectopic pregnancy distribution was consistent with large vessels in the female pelvic cavity $[1,12]$.

The ectopic heterotopic pregnancy was implanted in the psoas major muscle, and the length of the embryo bud was $25 \mathrm{~mm}$, which might be related to some key factors in the embryo implantation surroundings. During the process of the embryo moving from the uterus to the abdominal cavity and retroperitoneum, and further to the retrorenal space, and implanting in the psoas major muscle, a series of environments encountered by the embryo cannot be compared to that in the uterus. In surgery, the foetal bud was $25 \mathrm{~mm}$ long, which was equivalent to 9 weeks of pregnancy. This meant that the embryo had obtained nutrients in early development, but the specific mechanism of this obtainment was not clear. In addition, previous studies proposed that a history of pelvic surgery and ectopic pregnancy were risk factors for intraperitoneal pregnancy $[18,19]$. The case validated this view.

For the management of pregnancy patients after IVFET, attention has mostly been paid to the situation of the pelvic cavity to exclude ectopic pregnancy. The clinical manifestations of retroperitoneal pregnancy vary greatly, especially for rare heterotopic pregnancies. In this study, there was no discomfort in the upper abdomen and lumbar back initially. Therefore, the possibility of retroperitoneal pregnancy was ignored, and the diagnosis of heterotopic pregnancy was missed. This case also suggested that we should closely monitor any changes in $\beta$-hCG levels in the follow-up after embryo transfer. Especially for two embryo transfers, we should routinely investigate ectopic pregnancy in the pelvic and abdominal cavities, and for patients who undergo uterine curettage due to foetal arrest, we should closely monitor the decline in $\beta$-hCG after operation to further exclude rare ectopic pregnancy and trophoblastic diseases.
During the process of eliminating ectopic pregnancy, especially for rare ectopic pregnancy, ultrasound, CT and MRI are helpful in determining the existence of ectopic pregnancy and the anatomy around the gestational sac, which provided guidance in making a reasonable treatment plan. Meanwhile, the complaints of patients are important in clinical diagnosis and treatment.

The choice of therapeutic method (including open surgery, laparoscopic surgery and drugs) was based on the haemodynamics stability and the retention of intrauterine pregnancy. Generally, for patients with unstable haemodynamics and intrauterine pregnancy that needs to be simultaneously retained, surgical treatment is generally the first selection. The choice of surgical approach is also related to the experience of the surgeon, the position of the ectopic pregnancy and the experience with laparoscopic operation. However, for those with stable haemodynamics and intrauterine pregnancy that does not need to be preserved, drug treatment might be a choice, such as methotrexate, potassium chloride and hypertonic saline [20]. Singh Y et al. suggested that the placenta should be preserved locally to avoid bleeding and organ damage caused by stripping, but the disadvantage was that the risk of postoperative infection, secondary bleeding and even trophoblastic disease increased [21]. After removing the gestational sac implanted in the psoas major muscle, considering that trophoblasts might invade into the muscle layer, even if it was cleared as far as possible, the risk of bleeding will be greatly increased. Therefore, after gestational sac stripping, intramuscular injection with $10 \mathrm{mg}$ of methotrexate at the gestational sac implanting site was performed to kill residual trophoblasts. After the operation, regular follow-up was given to evaluate the recovery, and the decrease in $\beta$ hCG was slower than that in tubal pregnancy. It took 50 days for $\beta$-hCG to decrease to negative. Ansong E et al. [5] compared operation alone and operation combined with methotrexate (i.m. $50 \mathrm{mg} / \mathrm{m}^{2}$ ) for abdominal pregnancy, and the results showed that bleeding in the operation alone group was significantly higher, while the hospitalization time of the operation plus methotrexate (i.m. $50 \mathrm{mg} / \mathrm{m}^{2}$ ) group was significantly shortened. Therefore, if the local tissue is rich in blood supply, methotrexate (i.m. $50 \mathrm{mg} / \mathrm{m}^{2}$ ) could be given, especially for gestational sac implantation in rare sites, which could be helpful in killing trophoblast cells, decreasing $\beta$-hCG, and reducing relevant complications. The patient appreciated the treatment we provided for retroperitoneal pregnancy and the regular monitoring for recovery.

In summary, although the patient missed an early diagnosis of the rare heterotopic pregnancy, she was treated in time after showing clinical symptoms and obtained an ideal outcome. For pregnancy after embryo transfer in IVF, we should pay attention to the patient's 
main complaints and exclude ectopic pregnancy. Ultrasound examination should be commonly combined. If necessary, we could precisely locate the position of pregnancy sac implantation and the anatomy of the surroundings through CT and/or MRI and design a reasonable treatment plan for patient recovery. For rare site ectopic pregnancies, surgery combined with methotrexate is a good method, and how to combine these approaches deserves to be explored.

\section{Abbreviations}

hCG: Human chorionic gonadotropin; IVF-ET: In vitro fertilization-embryo transfer; CT: Computed tomography; MRI: Magnetic resonance imaging

\section{Acknowledgments}

Not applicable.

\section{Authors' contributions}

JF interpreted the patient data and wrote the first draft of the article. XPW and DM analyzed, interpreted the patient data and collaborated in the writing drafts. XQW critically reviewed and edited drafts. YGZ, YC, YXZ, ZL and XB collected materials and interpreted the patient data. All authors read and approved the final manuscript.

\section{Funding}

The study was supported by grants awarded to Junmei Fan by the "Hospital Fund of Shanxi Maternal and Child Health Care Hospital" (No 201727) and Xueqing Wu by "National Key Research and Development Program" (No 2018YFC1002103). Two founding organizations provided peer review of the study protocol and monitor the progress. Two founding organizations have no part in the collection, analysis, and interpretation of data and in writing the manuscript.

\section{Availability of data and materials}

All data analyzed during this study are included in this published article.

\section{Ethics approval and consent to participate}

The protocol was approved by the Ethics Committee of Shanxi Maternal and Child Health Care Hospital (IRB-KY-2017).

\section{Consent for publication}

The patient's written consent has been obtained for publication.

\section{Competing interests}

The authors declared that they have no conflict of interests.

\section{Author details}

${ }^{1}$ Children's Hospital of Shanxi and Women Health Center of Shanxi, Department of Reproductive Medicine Center, Taiyuan, Shanxi, China. ${ }^{2}$ Shanxi Bethune Hospital, Department of Urology, Taiyuan, Shanxi, China. ${ }^{3}$ Department of Obstetrics and Gynecology, Third Hospital, Peking University, Beijing, China.

Received: 14 March 2020 Accepted: 26 August 2020

Published online: 17 September 2020

\section{References}

1. Pak JO, Durfee JK, Pedro L, Osborne A, Larkins-Pettigrew M. Retroperitoneal ectopic pregnancy. Obstet Gynecol. 2018;132(6):1491-3.

2. Bouyer J, Coste J, Fernandez H, Pouly JL, Job-Spira N. Sites of ectopic pregnancy: a 10 year population-based study of 1800 cases. Hum Reprod. 2002;17(12):3224-30.

3. Atrash HK, Friede A, Hogue CJ. Abdominal pregnancy in the United States: frequency and maternal mortality. Obstet Gynecol. 1987;69(3 Pt 1):333-7.

4. $\quad X u Y, L u Y, C$ Chen H, Li D, Zhang J, Zheng L. Heterotopic pregnancy after in vitro fertilization and embryo transfer after bilateral total salpingectomy/ tubal ligation: case report and literature review. J Minim Invasive Gynecol. 2016;23(3):338-45
5. Ansong E, Illahi GS, Shen L, Wu X. Analyzing the clinical significance of postoperative methotrexate in the management of early abdominal pregnancy: analysis of 10 cases. Ginekol Pol. 2019;90(8):438-43.

6. Dzenita $\mathrm{L}$, Igor $\mathrm{H}$, Azra H. Heterotopic pregnancy in natural conception -our initial experience: case report. Acta Clin Croat. 2011;50(2):249-52.

7. Tal J, Haddad S, Gordon N, Timor-Tritsch I. Heterotopic pregnancy after ovulation induction and assisted reproductive technologies: a literature review from 1971 to 1993. Fertil Steril. 1996;66(1):1-12.

8. Altıntaş E, Yuksel B, Tok S, Hatipoglu H, Aslan F. Heterotopic pregnancy identified in the postpartum period. Int J Gynaecol Obstet. 2015;130(3):2878.

9. Cosentino F, Rossitto C, Turco LC, Gueli Alletti S, Vascone C, Di Meglio L, et al. Laparoscopic Management of Abdominal Pregnancy. J Minim Invasive Gynecol. 2017;24(5):724-5.

10. Kunwar S, Khan T, Srivastava K. Abdominal pregnancy: methods of hemorrhage control. Intractable Rare Dis Res. 2015;4(2):105-7.

11. Refaat $B$, Dalton $E$, Ledger WL. Ectopic pregnancy secondary to in vitro fertilisation-embryo transfer: pathogenic mechanisms and management strategies. Reprod Biol Endocrinol. 2015;13:30.

12. Ouassour S, Filali AA, Raiss M, Bezad R, Tazi Z, Alami MH, et al. Retroperitoneal ectopic pregnancy: diagnosis and therapeutic challenges. Case Rep Surg. 2017;2017:9871865.

13. Karkee R, Sharma A, Dangal B. Heterotopic pregnancy: a challenge in early diagnosis. J Nepal Health Res Counc. 2019;17(3):413-5.

14. Brewster EM Sr, Braithwaite EA, Brewster EM Jr. Advanced abdominal pregnancy: a case report of good maternal and perinatal outcome. West Indian Med J. 2011;60(5):587-9.

15. White RG. Advanced abdominal pregnancy--a review of 23 cases. Ir J Med Sci. 1989;158(4):77-8

16. Martínez-Varea A, Hidalgo-Mora JJ, Payá V, Morcillo I, Martín E, Pellicer A Retroperitoneal ectopic pregnancy after intrauterine insemination. Fertil Steril. 2011;95(7):2433.e1-3.

17. Iwama H, Tsutsumi S, Igarashi H, Takahashi K, Nakahara K, Kurachi H. A case of retroperitoneal ectopic pregnancy following IVF-ET in a patient with previous bilateral salpingectomy. Am J Perinatol. 2008;25(1):33-6.

18. Fatema N, Al Badi MM, Rahman M, Elawdy MM. Heterotopic pregnancy with natural conception; a rare event that is still being misdiagnosed: a case report. Clin Case Rep. 2016;4(3):272-5.

19. Jeon $\mathrm{JH}$, Hwang $\mathrm{Yl}$, Shin $\mathrm{H}$, Park $\mathrm{CW}$, Yang KM, Kim HO. The risk factors and pregnancy outcomes of 48 cases of heterotopic pregnancy from a single center. J Korean Med Sci. 2016;31(7):1094-9.

20. Ramalho I, Ferreira I, Marques JP, Carvalho MJ, Lobo A, Rebelo T, et al. Live birth after treatment of a spontaneous ovarian heterotopic pregnancy: a case report. Case Rep Womens Health. 2019;24:e00144.

21. Singh $Y$, Singh SK, Ganguly M, Singh S, Kumar P. Secondary abdominal pregnancy. Med J Armed Forces India. 2016;72(2):186-8.

\section{Publisher's Note}

Springer Nature remains neutral with regard to jurisdictional claims in published maps and institutional affiliations.

Ready to submit your research? Choose BMC and benefit from:

- fast, convenient online submission

- thorough peer review by experienced researchers in your field

- rapid publication on acceptance

- support for research data, including large and complex data types

- gold Open Access which fosters wider collaboration and increased citations

- maximum visibility for your research: over $100 \mathrm{M}$ website views per year

At $\mathrm{BMC}$, research is always in progress.

Learn more biomedcentral.com/submissions 